\title{
A INCONSTITUCIONALIDADE DA EMPRESA EDUCACIONAL NO BRASIL
}

\author{
THE UNCONSTITUTIONALITY OF EDUCACIONAL ENTERPRISE IN BRAZIL
}

LA INCONSTITUCIONALIDAD DE LA EMPRESA EDUCACIONAL EM BRASIL

\section{Guilherme Perez Cabral ${ }^{1}$}

RESUMO: O artigo tem como objetivo a reflexão hermenêutica sobre a constitucionalidade, no Brasil, da prestação da educação como atividade empresarial, orientada, portanto, à obtenção de lucro. A empresa educacional é amplamente adotada no país, com o amparo da legislação infraconstitucional, que estabelece a possibilidade de as mantenedoras de instituições de ensino assumirem o formato empresarial, fazendo, assim, da educação meio para a realização de sua finalidade lucrativa. A participação social na educação e, a ela ligada, a liberdade de ensinar da iniciativa privada são princípios estabelecidos pela Constituição Federal de 1988. Entretanto, referido texto, reconhecendo a educação como direito humano fundamental social, afirma também seu caráter de atividade pública, ainda que não privativa do Poder Público. Tem por objetivos "o pleno desenvolvimento da pessoa, seu preparo para o exercício da cidadania e sua qualificação para o trabalho". Realizada com base em pesquisa legislativa e bibliográfica, o artigo identifica que a participação da iniciativa privada na educação não pode se confundir - nem se corromper, portanto - com a empresa educacional. Por quem quer que seja realizada, a educação deve estar orientada aos objetivos constitucionalmente estabelecidos, não se admitindo, nesse sentido, sua instrumentalização em empreendimento econômico, deturpado por padrões de rentabilidade.

PALAVRAS-ChAVE: Direito à educação. Liberdade educacional. Empresa educacional.

ABSTRACT: The aim of this article is to examine, in hermeneutical terms, the constitutionality of the provision of education as a business activity in Brazil,. The educational enterprise is widely adopted in the country, under the protection of the infraconstitutional legislation, which alows the educational institutions maintainers assume the business configuration. In this way, they can make education a means to achieve its lucrative purpose. Social participation in education and the educational freedom are principles established by the Federal Constitution. It also recognizes education as a social human right and affirms its public activity character, which is not exclusive Public Power function. Its objectives are the full development of the person, his preparation for the exercise of citizenship and his qualification for work. Based on legislative and bibliographical research, the article identifies that the participation of private initiative in education cannot be confused - nor corrupted, therefore - with the educational enterprise. By whomever carried out, education must be oriented towards the constitutional aims, not allowing, in this sense, its instrumentalization in economic enterprise, distorted by profitability standards.

KEYWORDS: Right to education. Educational freedom. Educational enterprise.

RESUMÉN: El artículo tiene como objetivo la reflexión hermenéutica sobre la constitucionalidad, en Brasil, de la prestación de la educación como actividad empresarial, orientada, por lo tanto, a la obtención de lucro. La empresa educativa es ampliamente adoptada en el país, con el amparo de la legislación infraconstitucional, que establece la posibilidad de que las mantenedoras de instituciones de enseñanza asuman el formato empresarial, haciendo de la educación medio para la realización de su objetivo lucrativo. La participación social en la educación y, a ella ligada, la libertad de enseñar de la iniciativa privada son principios establecidos por la Constitución Federal de 1988. Sin embargo, dicho texto, reconociendo la educación como derecho humano fundamental social, afirma también su carácter de actividad pública, aún que no privativa del Poder Público. Tiene por objetivos "el pleno desarrollo de la persona, su preparación para el ejercicio de la ciudadanía y su

Submetido em: 28/08/2017 - Aceito em: 07/02/2018 - Publicado em: 09/02/2018.

\begin{tabular}{l|c|c|c|c|c|c} 
(C) Rev. Educ. Perspec. & Viçosa, $M G$ & v.8 & n.3 & AOP & set./dez. 2017 & eISSN 2178-8359 \\
\hline
\end{tabular}


cualificación para el trabajo". Realizada sobre la base de investigaciones legislativas y bibliográficas, el artículo identifica que la participación de la iniciativa privada en la educación no puede confundirse - ni corromper, por lo tanto - con la empresa educativa. Por quienquiera que sea realizada, la educación debe estar orientada a los objetivos constitucionalmente establecidos, no admitiéndose, en ese sentido, su instrumentalización en emprendimiento económico, distorsionado por patrones de rentabilidad.

PALABRAS CLAVE: Derecho a la educación. Libertad educativa. Empresa educativa.

\section{INTRODUÇÃO}

Construídos e reconstruídos na medida em que aplicados na regulação de condutas e na solução de conflitos, os sentidos dos textos jurídicos sofrem permanentemente influxos do contexto sobre o qual atuam. Nessa relação dialética, as formas do direito influenciam e, ao mesmo tempo, são influenciadas pela realidade da qual emergem e na qual funcionam.

Nesse sentido, o projeto jurídico-constitucional, dinamicamente compreendido, tem seus conteúdos revistos e renovados no seu processo de atualização. Numa perspectiva crítica, isso equivaleria "a interpretá-los melhor e a institucionalizá-los de modo mais apropriado e a esgotar de modo mais radical o seu conteúdo” (HABERMAS, 2011, p. 119).

No entanto, a efetividade da Constituição, a expressar a materialização de seus preceitos, no plano dos fatos, na "aproximação, tão íntima quanto possível, entre o dever ser normativo e o ser da realidade social” (BARROSO, 2016, p. 255, grifo do autor), pode significar não a realização de um projeto radical, mas, seu contrário, o esvaziamento completo de seus sentidos possíveis.

Noutros termos, o dever ser é controlado e condenado ao que é (ser), ante a força dos fatos e da história. O cumprimento da norma constitucional se perde na completa conformação dos sentidos extraídos do texto à realidade que o infirma - e que se pretendia, com o projeto de 1988, superar.

A Constituição Federal confere grande atenção à educação, reconhecida, diante da forma significativa como afeta a sociedade e seus membros, como matéria que extrapola a esfera privada das relações humanas e se reveste de um caráter eminentemente público. Afinal, interessa ao indivíduo, em vista de sua existência digna, com a realização de projetos pessoais, e interessa, também, à coletividade - o interesse de que os cidadãos, em certa medida pelo menos, sejam educados -, em vista do desenvolvimento do Estado democrático de direito e a consecução dos fins da República.

É afirmada, no Art. $6^{\circ}$ do texto constitucional, como direito fundamental social, inserindo, assim, sua realização (o ser educado), entre aquelas "propriedades que caracterizam o ser

\begin{tabular}{l|l|l|l|l|l|l} 
(C) Rev. Educ. Perspec. & Viçosa, $M G$ & v.8 & n.3 & AOP & set./dez. 2017 & eISSN 2178-8359 \\
\hline
\end{tabular}


humano constitutivamente como pessoa" (HONNETH, 2009, p. 188) e que, nessa medida, possibilitam uma vida digna.

Como tal, é assegurada mediante a prestação de serviços públicos, impondo-se aos atores que a ela se dedicam uma série de restrições e deveres. Dentre eles, destaca-se, aqui, a observância dos fins bastante precisos que a orientam: o "desenvolvimento pleno da pessoa, sua qualificação para o trabalho e seu preparo para o exercício da cidadania” (BRASIL, 1988, Art. 205). Na dialética de interesses (individual e social) que perpassam a educação, a formação da identidade - atendida em suas particularidades, preferências e potencialidades combina-se com a preparação para a participação efetiva na vida social, como cidadão e trabalhador.

Seu caráter público, sua configuração como um direito fundamental, os deveres que implica e os fins a que a se destina são mantidos mesmo quando a educação é prestada pela iniciativa privada. Não podia ser diferente. A prestação educacional no exercício de uma liberdade (a liberdade de educar) não retira tais traços constitucionalmente reconhecidos.

Ocorre que, no Brasil, a afirmação da liberdade, especificamente da livre iniciativa educacional, tem justificado a distorção do direito à educação, atingido em seus fins constitucionais. Com a chancela da legislação infraconstitucional - Lei de Diretrizes e Bases da Educação Nacional ( $n^{\text {o }}$ 9.394/1996) e a Lei nº 9.780/1999 -, atuam, no setor, sociedades empresariais (com fins lucrativos), denominadas instituições particulares.

No âmbito da educação básica, é verdade, predomina a escola pública, com o setor privado, lucrativo ou não, correspondendo a 21,5\% do total das matrículas (INEP, 2017). O cenário, todavia, muda no ensino superior, ou seja, 47,9\% das instituições de ensino superior brasileiras são empresárias (e-MEC, 2017). Respondem por aproximadamente $35 \%$ das matrículas em cursos de graduação (NUNES et. al., 2014).

Caracteriza-se, assim, antinomia lógica e jurídica. Empresa é a atividade exercida com o intuito de lucro. A prestação da educação por ator assim orientado direciona-a a objetivo distinto daqueles indicados no texto constitucional. Faz da educação instrumento do capital, meio para a obtenção de lucro.

É nesse contexto que o presente artigo reflete sobre a inconstitucionalidade da empresa educacional no Brasil, valendo-se, metodologicamente, de pesquisa legislativa e bibliográfica.

Para tanto, começa tratando da configuração jurídica da educação na Constituição Federal, analisando-a sob quatro perspectivas: o direito, o dever, os fins e o caráter público (1). Na sequência, ainda no plano constitucional, debruça-se sobre o conteúdo da liberdade

\begin{tabular}{l|l|l|l|l|l|l} 
(C) Rev. Educ. Perspec. & Viçosa, $M G$ & v.8 & n.3 & AOP & set./dez. 2017 & eISSN 2178-8359 \\
\hline
\end{tabular}


educacional (2). Passa-se, então, ao debate sobre a abertura jurídico-constitucional ao exercício da empresa educacional como aspecto da livre iniciativa (3), para se chegar, finalmente, à conclusão quanto à incompatibilidade dessa atividade lucrativa com os fins constitucionalmente atribuídos à educação (4).

\section{A EDUCAÇÃO NA CONSTITUIÇÃO FEDERAL DE 1988: O DIREITO, O DEVER, OS FINS E O CARÁTER PÚBLICO}

\section{O Direito}

Afirmada como direito social, a educação é regulamentada, de modo detalhado, em Seção específica da Constituição Federal (Título VIII, Capítulo III, Seção I) que começa com o Art. 205: “A educação, direito de todos e dever do Estado e da família, será promovida e incentivada com a colaboração da sociedade, visando ao pleno desenvolvimento da pessoa, seu preparo para o exercício da cidadania e sua qualificação para o trabalho" (BRASIL, 1988).

O direito de todos recebe contornos mais precisos no Art. 208, que, no inciso I, define-o, fundamentalmente, como "educação básica obrigatória e gratuita dos 4 (quatro) aos 17 (dezessete) anos de idade, assegurada inclusive sua oferta gratuita para todos os que a ela não tiveram acesso na idade própria".

Em relação aos níveis educacionais mais elevados, o acesso é condicionado à "capacidade de cada um" (BRASIL, 1988, inciso V).

\section{O Dever}

Repartem a tarefa de prestação da educação, assegurando o direito assim definido, o Estado, a família e a sociedade:

a) A esfera privada da família emerge como o momento inicial de aprendizagem e socialização da criança (DALLARI, 2009), de acordo com os valores, hábitos e conceitos próprios do núcleo familiar.

A instituição familiar, ressalta-se, conforme posicionamento adotado pelo Supremo Tribunal Federal, tem de ser apreendida como conceito aberto e não-reducionista, a comportar a pluralidade inerente à vida social e as distintas formas de composição de nosso espaço próprio e mais íntimo de afetividade. É, por isso, "palavra-gênero, insuscetível de antecipado fechamento conceitual das espécies em que pode culturalmente se desdobrar" (SUPREMO TRIBUNAL FEDERAL, 2011, p. 38). Faz-se, assim, como a ambiência necessária da 
educação naquele círculo das relações afetivas primárias que, com Axel Honneth, definem a esfera de reconhecimento do amor (HONNETH, 2009).

Ao lado desse ambiente formativo se coloca a educação escolar, desenvolvida em instituição própria, a escola, espaço institucional privilegiado e especialmente voltado à transmissão formal e sistematizada da tradição cultural do grupo social. É nela, então, que o educando extrapola a esfera privada da família, ingressando e interagindo no espaço público escolar ${ }^{1}$.

Nesse sentido, preveem os Artigos $5^{\circ}$, inciso III, e $6^{\circ}$ da Lei de Diretrizes e Bases, que os pais ou responsáveis têm o dever de matricular a criança na educação básica, a partir dos quatro anos de idade, zelando por sua frequência.

b) Ao Estado a Constituição Federal confere, dentre outras atribuições, o dever de prestar a educação, mantendo escolas.

Como direito fundamental social, a educação caracteriza-se como um direito a prestações por parte do Poder Público (SARLET et al., 2016). No caso, o ensino público, abrangendo, ao menos, a educação básica gratuita e obrigatória, tudo nos termos do supramencionado Art. 208.

c) No debate sobre a caracterização da educação como serviço público, afirmam alguns autores a preferência constitucional pelo ensino prestado pelo Poder Público (SILVA, 2016), sem, com isso, deixar de reconhecer, diante da expressa previsão constitucional, a abertura do setor à iniciativa privada.

Coloca-se, nesse cenário, a colaboração da sociedade que, diferentemente da atuação estatal e familiar, não aparece, propriamente, como o cumprimento de um dever. Efetiva-se, muito mais, como o exercício de uma liberdade.

A prática efetiva da cidadania, para além do voto obrigatório, contribuindo para o desenvolvimento social, não é algo que possa ser imposto pelo Estado democrático de direito. Isso vale, sem dúvida, para a participação social na educação, não só como prestador educacional, mas também como importante ator na formulação, organização, gestão e implantação da legislação e das políticas e serviços públicos educacionais, fazendo, desse modo, irradiar à educação o Estado democrático de direito (SILVA, 2016).

Cabe aos atores sociais a decisão livre se sairão do círculo dos próprios interesses e passarão pela mudança de perspectiva que os faça usar sua liberdade (uso público da liberdade) em prol da coletividade e dos objetivos da República (HABERMAS, 2012a). 
Os Fins

A prestação da educação é impregnada de deveres e responsabilidades, imposta a quem quer que a ela se dedique, seja no exercício de um dever, seja no de uma liberdade educacional. Citam-se, a título de exemplo, a observância da Lei de Diretrizes e Bases e demais normas gerais da educação; a garantia do padrão de qualidade (BRASIL, 1988, Art. 206, inciso VII), o cumprimento das diretrizes curriculares nacionais estabelecidas pelo Poder Público e, destaca-se neste artigo, os fins constitucionais da educação.

Referidos objetivos estão previstos na parte final do Art. 205 do texto constitucional. Conferindo relevo a três facetas do ser humano (HORTA, 2007), visa ao pleno desenvolvimento da pessoa, em sua individualidade e identidade; à sua qualificação como trabalhador; e, finalmente, à preparação para o exercício de seu papel de cidadão.

Iluminada pelos ideais e valores do projeto moderno emancipatório (CABRAL, 2016), o dispositivo retoma, em grande medida - como, aliás, a Constituição faz em relação aos direitos humanos fundamentais em geral - o previsto nos documentos que compõem o Direito Internacional dos Direitos Humanos.

Destaca-se, aqui, o Art. XXVI da Declaração Universal dos Direitos Humanos, o Art. 13 do Pacto Internacional sobre os Direitos Econômicos, Sociais e Culturais (ratificado pelo Brasil, em 1992, e promulgado pelo Decreto Federal nº 591/1992) e o Art. 13 do Protocolo Adicional à Convenção Americana sobre Direitos Humanos em matéria de Direitos Econômicos, Sociais e Culturais - "Protocolo de San Salvador" (ratificado pelo Brasil, em 1996, e promulgado por meio do Decreto Federal $n^{\text {o } 3.321 / 1999) . ~ A f i r m a m ~ o ~ d i r e i t o ~ d e ~ t o d a ~}$ pessoa à educação, ressaltando sua gratuidade e obrigatoriedade ao menos no nível fundamental, e estabelecem, como objetivos educacionais, o pleno desenvolvimento da pessoa e, ao mesmo tempo, sua capacitação para a participação efetiva na sociedade.

Eis os objetivos que, reconhecidos em tratados internacionais e incorporados ao texto constitucional, determinam, valendo-se da expressão habermasiana, a estruturação pedagógica da educação (HABERMAS, 2012b), impondo limites bastante precisos a qualquer instrumentalização da atividade educacional à consecução de outros fins e interesses.

\section{O Caráter Público}

Orientada aos aludidos objetivos, a educação se efetiva, como um direito humano fundamental, em benefício da pessoa, conferindo-lhe atributo sem o qual - assim reconhece o grupo social - não pode se constituir (como tal). Receber educação é apreendido coletivamente como condição para a vida e a convivência dignas. 
Por essa via, beneficia, também, como já destacava Marshall, a sociedade como um todo. Referindo-se à história da Inglaterra, afirma que "Tornou-se cada vez mais notório, com o passar do século XIX, que a democracia política necessitava de um eleitorado educado e que a produção científica se ressentia de técnicos e trabalhadores qualificados" (MARSHALL, 1967, p. 74).

Distinguem-se, com nitidez, de um lado a pretensão, socialmente reconhecida, do indivíduo, singularmente considerado em suas ambições e pretensões, de ter educação. De outro, a pretensão, apreendida como sendo da sociedade em geral, em vista de seu próprio desenvolvimento, de que seus cidadãos - pelo menos, numa certa medida - sejam educados.

A formação do indivíduo, apto à participação na vida cultural, econômica e política, ao mesmo tempo em que atualiza suas próprias potencialidades, habilitando-o ao exercício de outros direitos, promove o desenvolvimento do Estado e a consecução de seus objetivos fundamentais.

Prevista como um direito, a educação aparece, concomitantemente, como um "dever público de exercer o direito" (MARSHALL, 1967, p. 74). A educação básica, vimos, é obrigatória. Trata-se de um direito e de um dever. Impõe-se não só na perspectiva iluminista emancipatória - reconhecendo-se a indispensabilidade da formação racional do sujeito para a afirmação de sua individualidade e para a participação na vida social -, mas também frente à constatação pragmática de que "o bom funcionamento de uma sociedade depende da educação de seus membros" (MARSHALL, 1967, p. 74).

Justifica-se, enfim, a grande atenção dada ao tema educacional na Constituição Federal, identificada como um tema público.

Conforme a reflexão de John Dewey, a noção de público e a linha contextual e experimentalmente traçada que o distingue do que é privado emerge da identificação de efeitos, consequências das interações humanas cujo alcance e significação tornam necessário seu controle pela sociedade, seja pela inibição, pela promoção:

\footnotetext{
Quando as consequências de uma ação limitam-se ou são entendidas como limitadas sobretudo às pessoas nela diretamente envolvidas, a interação é privada (...) presumivelmente, as consequências da vantagem ou do dano não se estendem além de A e B; a atividade fica entre eles; ela é privada. Já se for constatado que as consequências da comunicação se estendem para além dos dois diretamente envolvidos, que ela afeta o bem-estar de muitos outros, o ato adquire uma capacidade de público (DEWEY, 1991, p. 12-13).
}

O caráter público atribuído à educação, dessa maneira, provém do reconhecimento de sua importância para a sociedade e seus membros. Porque suas consequências projetam-se de modo significativo sobre o grupo social, demanda, sob a perspectiva do próprio grupo, tê-la 
sistematicamente sob cuidado, valendo-se da linguagem do direito. Daí o robusto regramento constitucional, complementado pela legislação infraconstitucional.

É, destarte, um direito humano fundamental interpretado e configurado no espaço público. Sua prestação é um serviço público, independentemente de quem esteja se dedicando à sua realização. A prestação pela iniciativa privada, autorizada pela Constituição, não desqualifica a educação a ser prestada. Não lhe retira a importância que lhe é conferida e a regulamentação que lhe protege e controla.

\section{A LIBERDADE EDUCACIONAL NA CONSTITUIÇÃO DE 1988}

A liberdade educacional pode ser definida, de acordo com o Art. 206, inciso II, da Constituição Federal, como a "liberdade de aprender, ensinar, pesquisar e divulgar o pensamento, a arte e o saber" (BRASIL, 1988).

$\mathrm{Na}$ forma do dispositivo transcrito, é erigida a princípio constitucional da educação, abrangendo um conjunto de liberdades: a) a liberdade de produção e revisão do conhecimento, por meio da pesquisa; b) a liberdade de transmissão, divulgação e disseminação prática do conhecimento, por meio da atividade de ensino e, também, da de extensão. Este aspecto decorre e é reforçado, ainda, pela liberdade de "expressão da atividade intelectual, artística, científica e de comunicação, independentemente de censura ou licença", direito fundamental individual previsto no Art. 5\%, inciso IX, Constituição Federal; e, finalmente, c) a liberdade de busca e apreensão do conhecimento, em processos de aprendizagem.

Tudo a consagrá-la, de modo vigoroso, no texto constitucional. Na seção específica dedicada à educação, distinguem-se, ademais, duas esferas da liberdade educacional (CABRAL, 2017).

a) Primeiro, o que denominamos liberdade acadêmica, entendida como a prerrogativa atribuída aos professores e à comunidade escolar em geral de organizar, dirigir e efetivar o processo educativo, na escola pública ou privada. Em sua composição semântica, combinamse aos dispositivos supramencionados, o princípio constitucional da "pluralidade de ideias e concepções pedagógicas" (Art. 206, inciso III) e, finalmente, o da autonomia universitária ("autonomia didático-científica, administrativa e de gestão financeira e patrimonial"), afirmada no Art. 207 da Constituição e nele vinculada ao princípio da indissociabilidade entre ensino pesquisa e extensão (BRASIL, 1988).

b) Segundo a livre iniciativa educacional, isto é, a liberdade de o particular manter um estabelecimento e prestar o ensino. Intimamente relacionada à liberdade acadêmica e aos dispositivos que a regem, é reconhecida expressamente, entre os princípios constitucionais da

\begin{tabular}{l|c|c|c|c|c|c|} 
(C) Rev. Educ. Perspec. & Viçosa, $M G$ & v.8 & n.3 & AOP & set./dez. 2017 & eISSN 2178-8359 \\
\hline
\end{tabular}


educação, no Art. 206, inciso III, parte final, que estabelece a "coexistência de estabelecimentos públicos e privados de ensino" (BRASIL, 1988).

É-lhe dedicado, ademais, dispositivo específico, o Art. 209, segundo o qual "O ensino é livre à iniciativa privada, atendidas as seguintes condições: I - cumprimento das normas gerais da educação nacional; II - autorização e avaliação de qualidade pelo Poder Público" (BRASIL, 1988).

Significa dizer: o prestador educacional privado - em realidade, não só ele, a escola pública também - deve cumprir, com rigor, a Lei de Diretrizes e Bases e demais normas da educação, submetendo-se periodicamente aos processos avaliativos e regulatórios realizados pelos órgãos públicos responsáveis. Desse modo, afere-se o atendimento da legislação e, ainda, a observância do padrão de qualidade, exigido conforme o Art. 206, inciso VII do texto constitucional.

Não se trata, como se vê, de liberdade irrestrita. Recebe, ainda no texto constitucional, significativas e incontestáveis limitações, decorrências necessárias do sentido assumido pela educação e importância a ela conferida. Trata-se, afinal, de matéria pública, referida a direito fundamental que, como destacado, tem seus objetivos constitucionalmente especificados.

A prática da educação, no Brasil, não pode perder, jamais, tais referências, mesmo quando prestada pelos particulares no exercício da liberdade de educar.

\section{A EMPRESA EDUCACIONAL}

O sistema econômico adotado no Brasil, não se questiona, é o capitalismo. Em nosso ordenamento jurídico, os elementos essenciais do modo de produção capitalista têm guarida constitucional.

A livre iniciativa está prevista como fundamento da República (Art. $1^{\circ}$, inciso IV) e, no Art. 170, como fundamento da ordem econômica. A propriedade privada é direito fundamental, afirmado duas vezes no Art. 5ㅜㅡ, no caput e no inciso XXII, e retomado, depois, como princípio geral da atividade econômica, juntamente com a livre concorrência (Art. 170, incisos II e IV) (BRASIL, 1988).

Finalmente, o parágrafo único do Art. 170 assegura "o livre exercício de qualquer atividade econômica, independentemente de autorização de órgãos públicos, salvo nos casos previstos em lei" (BRASIL, 1988). 
Resguarda, assim, como regra geral, aos agentes econômicos, a liberdade de exercício de empresa, legalmente definida, Art. 966 do Código Civil, como a atividade econômica organizada para a produção ou a circulação de bens ou de serviços.

Corresponde, pois, à "atividade, cuja marca essencial é a obtenção de lucros com o oferecimento ao mercado de bens ou serviços, gerados estes mediante a organização dos fatores de produção (força de trabalho, matéria-prima, capital e tecnologia)" (COELHO, 2016, p. 38).

Entretanto, produzir e fazer circular bens e serviços, para lucrar, não são direitos absolutos. Mesmo as liberdades fundamentais e os elementos essenciais da ordem econômica capitalista sofrem limitações na ordem jurídico-constitucional brasileira.

Se, de fato, a Constituição assegura e estimula a atividade empresarial, num ambiente de livre iniciativa, livre concorrência e de respeito à propriedade privada, compõe esses direitos, mitigando-os, com princípios como a dignidade da pessoa humana, fundamento da República Federativa do Brasil, nos termos do Art. $1^{\underline{0}}$, com a função social da propriedade e com tantos outros direitos humanos fundamentais, dentre os quais a educação. Tudo, a indicar, na afirmação de José Afonso da Silva, a "compreensão de que o capitalismo concebido há de se humanizar (se que isso seja possível)" (SILVA, 2016, p. 766).

No que se refere aos serviços educacionais, a prestação como empreendimento empresarial não encontra, é verdade, vedação expressa no texto constitucional.

A possibilidade, por isso - poder-se-ia argumentar, em primeira análise, superficial - estaria abrangida no espaço da liberdade, não limitada pela lei, o instrumento por excelência para a garanti-la e regulá-la (SARLET et. al., 2016). É o princípio da legalidade: ninguém é obrigado a fazer ou deixar de fazer alguma coisa senão em virtude de lei (BRASIL, 1988, Art. $5^{\circ}$, inciso II).

Pode, ademais, ser aventada considerando prerrogativas atribuídas exclusivamente a escolas sem finalidade lucrativa. Nessa linha: a vedação de instituição de impostos sobre o "c) patrimônio, renda ou serviços (...) das instituições de educação e de assistência social, sem fins lucrativos" (BRASIL, 1988, Art. 150, inciso IV, alínea "c", grifo nosso) e a destinação de recursos públicos, na forma do Art. 213:

Art. 213. Os recursos públicos serão destinados às escolas públicas, podendo ser dirigidos a escolas comunitárias, confessionais ou filantrópicas, definidas em lei, que:

I - comprovem finalidade não-lucrativa e apliquem seus excedentes financeiros em educação; 
II - assegurem a destinação de seu patrimônio a outra escola comunitária, filantrópica ou confessional, ou ao Poder Público, no caso de encerramento de suas atividades (BRASIL, 1988, grifo nosso).

O reconhecimento de alguns direitos apenas para as instituições privadas não empresárias sugere, enfim, a presença no setor, também, de instituições lucrativas, somente estas obrigadas ao pagamento dos impostos referidos no Art. 150 e excluídas da destinação de recursos públicos.

Nesse cenário, a liberdade empresarial no campo da educação foi, aos poucos, ganhando corpo nos textos normativos infraconstitucionais.

A Lei de Diretrizes e Bases da Educação Nacional, aprovada em 1996, regulamenta a escola privada sem fazer, num primeiro momento, nenhuma diferenciação entre instituições com e sem finalidade lucrativa (BRASIL, 1996).

Distingue duas categorias administrativas de instituições de ensino, as públicas "assim entendidas as criadas ou incorporadas, mantidas e administradas pelo Poder Público" e as privadas "assim entendidas as mantidas e administradas por pessoas físicas ou jurídicas de direito privado” (BRASIL, 1996, Art. 19).

No Art. 20, então, apresenta classificação das instituições privadas, reconhecendo quatro categorias:

I - particulares em sentido estrito, assim entendidas as que são instituídas e mantidas por uma ou mais pessoas físicas ou jurídicas de direito privado que não apresentem as características dos incisos abaixo;

II - comunitárias, assim entendidas as que são instituídas por grupos de pessoas físicas ou por uma ou mais pessoas jurídicas, inclusive cooperativas de professores e alunos que incluam na sua entidade mantenedora representantes da comunidade; III - confessionais, assim entendidas as que são instituídas por grupos de pessoas físicas ou por uma ou mais pessoas jurídicas que atendem a orientação confessional e ideologia específicas e ao disposto no inciso anterior;

IV - filantrópicas, na forma da lei (BRASIL, 1996).

Qualquer obscuridade é definitivamente superada pelo então Presidente Fernando Henrique Cardoso. Regulamentando o sistema federal de ensino, estabelece, por meio do Decreto Federal n⿳0 2.207/1997, a possibilidade de constituição das instituições de ensino superior privadas como "sociedades mercantis" (empresariais), nos termos do Art. 16, inciso II, Código Civil de 1916 (BRASIL, 1997).

A medida se coadunava com a política educacional neoliberal adotada no país a partir da década de 1990, abrangendo a identificação da educação superior como serviço comercial enfraquecendo-o como direito fundamental -, na linha da agenda do Acordo Geral de Comércio e Serviços da Organização Mundial do Comércio (SGUISSARD, 2015). 
Ainda em 1997, a regra ganha força de lei, com a Medida Provisória $\mathrm{n}^{0}$ 1.477, inúmeras vezes reeditada, até a conversão na Lei $\mathrm{n}^{\mathrm{o}}$ 9.870, em 1999. Acrescentando dispositivos à Lei $\mathrm{n}^{\mathrm{o}}$ 9.131/1995, estabelece que as pessoas jurídicas de direito privado, mantenedoras de instituições de ensino superior privadas, previstas no Art. 19, inciso II, da Lei de Diretrizes e Bases, "poderão assumir qualquer das formas admitidas em direito, de natureza civil ou comercial” (BRASIL, 1996).

Em relação às demais espécies de entidades mantenedoras de instituições privadas de ensino superior, estabelece, em conformidade com o acima transcrito Art. 213, inciso I, da Constituição Federal, que não poderão ter finalidade lucrativa.

Formata-se, assim, o quadro das instituições educacionais no Brasil. No âmbito das instituições privadas, mantidas e administradas por pessoas físicas e jurídicas de direito privado, destaca-se a subdivisão: as instituições com finalidade lucrativa (empresárias) e, abrangendo as comunitárias, as confessionais e as filantrópicas (ou instituições beneficentes de assistência social), as instituições sem finalidade lucrativa.

Em 2009, tal configuração é finalmente assumida na Lei de Diretrizes e Bases, abrangendo todos os níveis educacionais. Isso ocorre com a alteração do Art. 20, inciso II, que destaca, como elemento distintivo das instituições comunitárias (extensivo às confessionais), a constituição "sem fins lucrativos".

Assim se configura o quadro jurídico e hermenêutico brasileiro, admitindo-se, sem maiores questionamentos, a prestação empresarial da educação.

É leitura que confirma e dá cores de juridicidade e constitucionalidade à prática, marcada pela significativa presença dos empresários tanto na educação básica como, de maneira mais expressiva, na educação superior, onde respondem por mais de um terço das matrículas de graduação.

\section{A INCONSTITUCIONALIDADE DA EMPRESA EDUCACIONAL}

Ocorre que a estruturação pedagógica da educação exige, mais do que a observância de normas gerais infraconstitucionais, sua harmonização com a Constituição Federal lida sistematicamente, como texto único e fundamental.

A atividade interpretativa, de atribuição de sentidos aos textos normativos, é, sempre, uma ação construtiva. O intérprete constrói e reconstrói o texto, na medida em que o aplica,

\begin{tabular}{l|l|l|l|l|l|l} 
(C) Rev. Educ. Perspec. & Viçosa, $M G$ & v.8 & n.3 & AOP & set./dez. 2017 & eISSN 2178-8359 \\
\hline
\end{tabular}


trazendo consigo, na composição do sentido, elementos axiológicos, históricos, políticos e econômicos (BITTAR, 2010).

Isso não implica, porém, a afirmação de uma atividade arbitrária. Reconhecer que o sujeito da interpretação lhe confere sentidos, não quer dizer que a prática de significação está submetida à arbitrariedade. Há limites, agindo o intérprete "dentro de um campo de forças. Dizer o contrário é aceitar que o discurso é uma realidade sem fronteiras” (BITTAR, 2010, 126-127).

Dentre as balizas para prática hermenêutica, reconhecidos pelos intérpretes do direito - que compõem a denominada "doutrina" e jurisprudência - vale destacar o princípio da unidade da Constituição. É o princípio de acordo com o qual a Constituição "representa uma unidade, um todo indivisível", não podendo, portanto, ser lida "em tiras, aos pedaços isolados" (SARLET et. al., 2016, p. 215-216).

Demanda do intérprete, destarte, para a concretização do dever ser constitucional, a harmonização das tensões e contradições entre as normas, operando a concordância prática entre os bens jurídicos tutelados em conflitos e preservando, ao máximo, cada um deles (BARROSO, 2016; SARLET et. al., 2016).

Nesse sentido, não se pode negar, absolutamente, o direito de o particular manter uma escola e, ainda, o direito do educando e de seus responsáveis de optar pela frequência em escola privada.

São decorrências do princípio da liberdade educacional, garantida pela Constituição, como visto, nos Artigos 206, inciso III, e 209. Trata-se de princípio que, vale acrescentar, coadunase com os compromissos assumidos pelo Brasil no Pacto Internacional de Direitos Econômicos, Sociais e Culturais:

\footnotetext{
Os Estados Partes do presente Pacto comprometem-se a respeitar a liberdade dos pais e, quando for o caso, dos tutores legais de escolher para seus filhos escolas distintas daquelas criadas pelas autoridades públicas, sempre que atendam aos padrões mínimos de ensino prescritos ou aprovados pelo Estado (...).

Nenhuma das disposições do presente artigo poderá ser interpretada no sentido de restringir a liberdade de indivíduos e de entidades de criar e dirigir instituições de ensino, desde que respeitados os princípios enunciados no parágrafo 1 do presente artigo e que essas instituições observem os padrões mínimos prescritos pelo Estado (BRASIL, 1992).
}

Contudo, como visto, a prestação educacional, no exercício da livre iniciativa, demanda o atendimento dos princípios, normas e, ressalta-se aqui, os fins precisos e bem definidos conferidos, no texto constitucional, ao direito humano fundamental à educação. 
Repisa-se. Por quem quer que seja efetivada, a educação deve ser orientada "ao desenvolvimento pleno da pessoa, sua qualificação para o trabalho e seu preparo para o exercício da cidadania" (BRASIL, 1988). Eis seus objetivos.

Trata-se de conceitos - os aludidos objetivos constitucionais e a garantia da liberdade educacional - que podem, sim, coexistir na prática. Harmonizam-se no irrecusável reconhecimento da iniciativa privada no setor, com importante ressalva: a proibição de se valer desta atividade como meio para a consecução de outra finalidade, não educacional.

O lucro não pode ser o fim da prestação da educação, portanto. É uma conclusão lógica e jurídica, decorrência de interpretação sistemática da Constituição Federal. A finalidade lucrativa da empresa é incompatível com a educação, constitucionalmente concebida. A Constituição Federal admite a escola privada, que resguarda e atende aos cuidados e interesses públicos que caracterizam o serviço prestado, mas não a empresa educacional.

Afinal, ao se dedicar a qualquer atividade econômica, o empresário tem intuito bastante específico, o lucro. Este é o fim. A atividade empresarial é organizada para a obtenção de rentabilidade. É lucrativa, por definição. E se o fim é o lucro, deixa de ser os objetivos da educação, atendidos apenas na medida não impede os ganhos do empreendedor. Por isso,

Na maioria das instituições privadas não existe, de fato, liberdade acadêmica, para os docentes, isto é, de ensino e pesquisa, pois a criação de cursos, o currículo e até as ementas das disciplinas oferecidas são controladas pela mantenedora, do mesmo modo que as raras pesquisas existentes. É também a mantenedora que fixa o número de vagas e o tamanho das turmas e, como os recursos (e os lucros) provêm das mensalidades, o interesse dessas universidades é o de ampliar exorbitantemente o número de vagas (DURHAN, 2005, p. 06).

A escola empresarialmente organizada, monetarizada (HABERMAS, 2012b), tem de ser estruturada de acordo com as demandas imediatistas do mercado e o interesse de acumulação do capital. "Escravizada" por fatores alheios à educação, não pode ser "livre" para a consecução de seus fins, como explicava Anísio Teixeira:

\footnotetext{
Veja-se bem que não identifico educação privada ou particular com educação livre. Livre, pela Constituição, é a iniciativa privada de oferecer educação. Mas tal educação privada está, entre nós, mais do que a pública, sujeita a imposições alheias à própria educação. De modo geral, entretanto, as suas escravizações mais visíveis são, exatamente, ao preconceito e ao dinheiro. Quanto a este, a educação privada é, por excelência, uma educação barata. Precisa e tem de ser barata. Faz-se por isso mesmo rotineira, conservadora e hostil a inovações e experiências. Quanto ao preconceito, a escola privada faz-se escrava de sua clientela. Está ali para satisfazêla, para atendê-la, para obedecer-lhe (TEIXEIRA, 1960, p. 19).
}

A empresa educacional, enfim, implica a instrumentalização da educação, em prejuízo do direito a que corresponde. Corrompendo-a, faz dela meio, negócio privado, direcionado ao lucro do empresário. 


\section{CONSIDERAÇÕES FINAIS}

Assim, na hermenêutica jurídico-constitucional brasileira, a afirmação da liberdade educacional pode funcionar como argumento para que o prestador privado se esquive do dever de educar.

O empresário pode prestar serviços educacionais, sem se preocupar com a concretização plena do direito humano fundamental, orientado a fins específicos constitucionalmente previstos.

Estes não são seus objetivos. Efetiva educação naquilo que é absolutamente necessário para atuar no setor - submetendo-se, por isso, aos processos de autorização e avaliação - e não prejudica o lucro.

A ideia de liberdade (a livre iniciativa) sobrepõe-se e mitiga a educação como direito e o dever correspondente. A efetivação da liberdade implica a privatização da educação, esvaziando-a de seu caráter público. Desqualifica-a, reduzindo os cuidados que demandaria e enfraquecendo a regulamentação que a protege.

A Constituição perde, neste campo, seu vigor como projeto de sentidos sempre mais plenos e enriquecidos. As significações são empobrecidas, com o reconhecimento jurídico de interesses e fins econômicos, no exercício da educação, que nada têm a ver com ela.

A educação e seus objetivos de pleno desenvolvimento da pessoa, a qualificação para o trabalho e o preparo para o exercício da cidadania tornam-se significantes tão esvaziados que podem coexistir com a noção de negócio para lucro do mantenedor. Não se distinguem mais.

Em última análise, afirmar a educação pode significar, sem constrangimentos, com coerência chancelada pelo intérprete do direito, negá-la.

\section{REFERÊNCIAS}

ALMEIDA, Guilherme de Assis. Aula ministrada na disciplina Direitos humanos fundamentais do Programa de Pós-Graduação Stricto Sensu em Direito da Universidade de São Paulo. São Paulo, 29 abr. 2013.

BARROSO, Luís Roberto. Curso de direito constitucional contemporâneo. Os conceitos fundamentais e a construção do novo modelo. 5ª ed. São Paulo: Saraiva, 2016.

BITTAR, Eduardo Carlos Bianca. Linguagem jurídica. São Paulo: Saraiva, 2010.

\begin{tabular}{l|c|c|c|c|c|c} 
(C) Rev. Educ. Perspec. & Viçosa, $M G$ & v.8 & n.3 & AOP & set./dez. 2017 & eISSN 2178-8359 \\
\hline
\end{tabular}


BRASIL. Constituição Federal de 1988. Promulgada em 5 de outubro de 1988. Disponível em: 〈http://www.planalto.gov.br/ccivil_03/constituicao/constituição.htm>. Acesso em: 26 agos. 2017.

BRASIL. Lei de Diretrizes e Bases da Educação Nacional (LDBEN). Lei n. 9.394, de 20 de dezembro de 1996. Estabelece as diretrizes e bases da educação nacional. Disponível em: <http://www.planalto.gov.br/ccivil_03/leis/19394.htm>. Acesso em: 26 agos. 2017.

BRASIL. Decreto no 2.207, de 15 de abril de 1997. Regulamenta, para o Sistema Federal de Ensino, as disposições contidas nos arts. 19, 20, 45, 46 e $§ 1^{\circ}$, 52, parágrafo único, 54 e 88 da Lei n. 9394, de 20 de dezembro de 1996, e dá outras providências. Disponível em: <http://www2.camara.leg.br/legin/fed/decret/1997/decreto-2207-15-abril-1997-445065publicacaooriginal-1-pe.html>. Acesso em: 26 agos. 2017.

BRASIL. Decreto $\mathbf{n}^{0}$ 591, de 6 de julho de 1992. Atos Internacionais. Pacto Internacional sobre Direitos Econômicos, Sociais e Culturais. Promulgação. Disponível em: <http://www.planalto.gov.br/ccivil_03/decreto/1990-1994/d0591.htm >. Acesso em: 26 agos. 2017.

BRASIL. Lei $\mathbf{n}^{\mathbf{0}}$ 12.101, de 27 de novembro de 2009. Dispõe sobre a certificação das entidades beneficentes de assistência social; regula os procedimentos de isenção de contribuições para a seguridade social; altera a Lei $n^{0}$ 8.742, de 7 de dezembro de 1993; revoga dispositivos das Leis $\mathrm{n}^{\mathrm{os}} 8.212$, de 24 de julho de $1991,9.429$, de 26 de dezembro de 1996, 9.732, de 11 de dezembro de 1998, 10.684, de 30 de maio de 2003, e da Medida Provisória n⿳ํㅡㄹ 2.187-13, de 24 de agosto de 2001; e dá outras providências. Disponível em: <http://www.planalto.gov.br/ccivil_03/_ato2007-2010/2009/lei/112101.htm>. Acesso em: 26 agos. 2017.

CABRAL, Guilherme Perez. "Educação na e para a democracia no Brasil: considerações a partir de J. Dewey e J. Habermas”. Educação \& Sociedade, Campinas, v. 37, n. 136, p. 873889, set. 2016.

CABRAL, Guilherme Perez. A história da educação e do direito à educação no Brasil. In: BITTAR, Eduardo Carlos Bianca (Org.). História do direito brasileiro: leituras da ordem jurídica nacional. 4 ed. São Paulo: Atlas, 2017.

COELHO, Fábio Ulhoa. Curso de direito comercial. Direito de empresa. v. 1, 20. ed. São Paulo: Revista dos Tribunais, 2016

DALLARI, Dalmo de Abreu. "Educação e preparação para a cidadania". In: BENEVIDES, Maria Victoria de Mesquita; BERCOVICI, Gilberto; MELO, Claudinei de. Direitos humanos, democracia e república: homenagem a Fábio Konder Comparato. São Paulo: Quartier Latin, 2009.

DEWEY, John. The public and its problems. Swallow Press/Ohio University Press/Athens, 1991. 
DURHAN, Eunice Ribeiro. A autonomia universitária - extensão e limites. Núcleo de Pesquisas sobre Ensino Superior - NUPES, Universidade de São Paulo, 2005.

HONNETH, Axel. Luta por Reconhecimento. A gramática moral dos conflitos sociais. 2. ed. São Paulo: Editora 34, 2009.

HABERMAS, Jürgen. Direito e democracia: entre factibilidade e validade. v. 2. Trad. Flávio Beno Siebeneichler. Rio de Janeiro: Tempo Brasileiro, 2011.

HABERMAS, Jürgen. Direito e democracia: entre factibilidade e validade. v. 1, 2. Ed. Trad. Flávio Beno Siebeneichler. Rio de Janeiro: Tempo Brasileiro, 2012a.

HABERMAS, Jürgen. Teoria do agir comunicativo. Sobre a crítica da razão funcionalista. Tomo 02. Trad. Flávio Beno Siebeneichler. São Paulo: Editora WMF Martins Fontes, 2012b.

HORTA, José Luiz Borges. Direito Constitucional da Educação. Belo Horizonte: Decálogo, 2007.

INSTITUTO NACIONAL DE ESTUDOS E PESQUISAS EDUCACIONAIS “ANÍSIO TEIXEIRA” (INEP). Censo escolar da educação básica 2016. Notas Estatísticas. Brasília/DF, 2017. Disponível em:

<http://download.inep.gov.br/educacao_basica/censo_escolar/notas_estatisticas/2017/notas_e statisticas_censo_escolar_da_educacao_basica_2016.pdf>. Acesso em: 26 agos. 2017.

MARSHALL, Thomas Humprey. Cidadania, classe social e status. Trad. Meton Porto Gadelha. Rio de Janeiro: Zahar, 1967.

NUNES, Edson de Oliveira. Regulação e Ensino Superior no Brasil. Documento de Trabalho $\mathrm{n}^{\mathrm{o}}$ 112. Disponível em:

$<$ http://www.observatoriouniversitario.org.br/documentos_de_trabalho/documentos_de_traba lho_112.pdf>. Acesso em: 26 agos. 2017.

SARLET, Ingo Wolfgang; MARINONI, Guilherme. Curso de direito constitucional. São Paulo: Saraiva, 2016.

SUPREMO TRIBUNAL FEDERAL. Ministro Relator Ayres Brito. Ação Direta de Inconstitucionalidade n⿳0 4.277/Distrito Federal. Data do julgamento: 05 maio 2011.

SGUISSARD, Valdemar. Educação superior no Brasil: democratização ou massificação. Educação \& sociedade, Campinas, v. 36, n. 133, p. 867-889, out/dez., 2015.

SILVA, José Afonso da. Curso de direito constitucional positivo. 39. ed. São Paulo: Malheiros, 2016.

TEIXEIRA, Anísio. A nova Lei de Diretrizes e Bases: um anacronismo educacional. Rio de Janeiro, v. 1, n. 1, jan./mar. 1960.

\begin{tabular}{l|c|c|c|c|c|c} 
(C) Rev. Educ. Perspec. & Viçosa, $M G$ & v.8 & n.3 & AOP & set./dez. 2017 & eISSN 2178-8359
\end{tabular}




\section{NOTAS}

${ }^{1}$ Guilherme de Assis Almeida identifica a escola, nesse sentido, como lugar de efetivação do direito da criança ao espaço público (ALMEIDA, 2013).

${ }^{2}$ Em relação às filantrópicas, ou entidades beneficentes de assistência social, a ausência de finalidade lucrativa como elemento de sua definição, aparece, na legislação infraconstitucional, no Art. 1ํ da Lei 12.101/2009: “A certificação das entidades beneficentes de assistência social e a isenção de contribuições para a seguridade social serão concedidas às pessoas jurídicas de direito privado, sem fins lucrativos, reconhecidas como entidades beneficentes de assistência social com a finalidade de prestação de serviços nas áreas de assistência social, saúde ou educação, e que atendam ao disposto nesta Lei” (BRASIL, 2009).

\section{Sobre o Autor}

Guilherme Perez Cabral: Professor-pesquisador da Pontifícia Universidade Católica de Campinas, Mestre em Direito pela Universidade Metodista de Piracicaba e Doutor em Direito pela Universidade de São Paulo. E-mail: gpcabral@gmail.com 